\title{
Changing the way to insert peritoneal catheters
}

\begin{abstract}
To achieve good results with Peritoneal Dialysis (PD) treatment is necessary to have a successful peritoneal catheter. There are many ways to insert them: laparoscopic, open access, peritenoscopia...the important point for nephrologists is trying to develop one or maximum (if you can) two ways to place the catheter and bet for it. The problem may appear when you have to change your "thieoretical" way to place the catheter due to external factors that don't depend on you. Laparoscopic procedure had been in our hospital the only way to place catheters for years. The increasing incidence of oncological patients, oblige surgeons to concentrate their work on them and leaving out "easiest" procedures like placing peritoneal catheters. When this happened, we had to change completely the procedure and tried convince Interventional Radiologist to learn how to place those catheters and started to do it. This "change" last for one year more or less. After four years, our experience is very good as complications are minimum when the catheter is placed by Radiologists, many complicated patients that wouldn't had been optimum for laparoscopic procedure had started PD without problems and we had initiated patients with a semi-urgent start in PD. Even more, Radiological placement is a cheaper procedure and we had been able to save money to local Health System
\end{abstract}

We present in this study our results.
Volume 7 Issue I - 2019

\author{
I Garcia,' A Gelabert,' J Codina,' D \\ Preciado,' C Noboa, ${ }^{2}$ M Castillo ${ }^{2}$ \\ 'Department of Radiology, Residencia Sanitaria Álvarez de \\ Castro, Spain \\ ${ }^{2}$ Department of Nephrology, Residencia Sanitaria Álvarez de \\ Castro, Spain
}

Correspondence: I Garcia, Nephrology \& Radiology Hospital Trueta, Girona, Spain, Email isabel0408@yahoo.es

Received: January 30, 2019 | Published: February 28, 2019

\section{Introduction}

Peritoneal dialysis is one of the treatments used for the last stage of Chronic Kidney disease. The peritoneal cavity is used to fill it with special dialysis fluids that remove toxins from blood through peritoneal membrane. It is crucial to introduce an special catheter to peritonal cavity. It may be placed by many techniques depending on health esources, on experience, etc.. ${ }^{1,2}$ Many studies have demonstrated the advantages/disadvantages of each technique but none of them is better than the others. Problems may appear when for some unexpected reason you have to change to another placement technique that you don't control. One example is the growing incidence of gastro-intestinal neoplasias that occupies almost the whole time of surgeons and "less-important" procedures are relegated. ${ }^{3-5} \mathrm{We}$ explain our experience about the placement of peritoneal catheter by Interventional Radiologists after more than ten years of laparoscopic insertion by General Surgeons. We compare the results of techniques, complications and the cost for health system

\section{Material and methods}

The surgical way to introduce the catheter was by laparoscopy with the use of two ports. General anesthesia is needed to realize this procedure as a one-two day-stage at the hospital On the other hand, Interventional Radiologist use direct puncture (Seldinger method) with scope control. No general anesthesia is needed and usually is an ambulatory procedure. The demographic data of all patients who had received a peritoneal catheter from 2007 to date at Trueta Hospital in Girona are collected. Catheter's survival placed is evaluated. The incidence of immediate post-placement complications (hemorrhage, infection, leakage and non-immediate functioning) as well as longterm (obstruction, hernias) one's is determined. Regarding the cost, the price of the whole procedure is calculated according to local Health taxes.

\section{Results}

During these 10 years, 251 catheters have been placed: by surgeons $166 /$ by radiologists 85 . The survival comparing the two methods did not show significant differences being $95 \%$ in both techniques first year regarding immediate and late complications results are shown in the next Table:

\begin{tabular}{lll}
\hline & Surgery $n=166$ & Radiol. $n=85$ \\
\hline Early disfunción & $3 \%$ & $1,2 \%$ \\
Late disfunción & $7 \%$ & $2 \%$ \\
Early infection & $0,6 \%$ & $1,2 \%$ \\
Leakage & 0 & $7 \%$ \\
Intestinal perforation & 0 & $2,3 \%$ \\
Hemorrhage & 0 & 0
\end{tabular}

The global cost for the surgical procedure is 1.580 Euros and 972 for Radiological one. Having changed the way of placement, our hospital has saved 69.220 Euros. In addition, a group of special patients with many comorbidites can choose peritoneal dialysis as no general anesthesia is needed.

\section{Conclusion}

a. In our hospital both placement techniques have very good results with few complications

b. A higher proportion of late dysfunction is seen with surgeryProbably in relation with adherences

c. Leakage was more frequent with radiologic procedure but it was during the first cases. The methodology placement was modified and this complication disappeared

d. The procedure done by Radiologist is very efficient as it safes a big amount of money PD is offered to those patients in whom general anesthesia is contraindicated.

\section{Acknowledgments}

None

\section{Conflicts of interest}

Authors declare there is no conflict of interest.

\section{References}

1. Hideaki Oka, Shunsuke Yamada, Masatoshi Hara, et al. Modified Simple Peritoneal Wall Anchor Technique (PWAT) in Peritoneal Dialysis. Perit Dial Int. 2017;37(1):103-108. 
2. Mohammad Reza Keramati, Ali Abbaszadeh-Kasbi, Amir Keshvar Laparoscopic Omentopexy, Rectus Sheath Tunneling and Implantation of the Peritoneal Dialysis Catheter Using a Peritoneal Dialysis Port. Perit Dial Int. 2018;38(3):187-191.

3. Shrestha BM, Shrestha D, Kumar A, et al. Advanced Laparoscopic Peritoneal Dialysis Catheter Insertion: Systematic Review and MetaAnalysis. Perit Dial Int. 2018;38(3):163-171.
4. Brunier G, Hiller JA, Drayton S, et al. A change to radiological peritoneal dialysis catheter insertion: three-month outcomes. Perit Dial Int. 2010;30(5):528-533.

5. Garcia I, Farres R, Ramón F, et al. Laparoscopia como técnica eficaz para la colocación del catéter peritoneal. Nefrologia. 2013;33(1):137-138. 